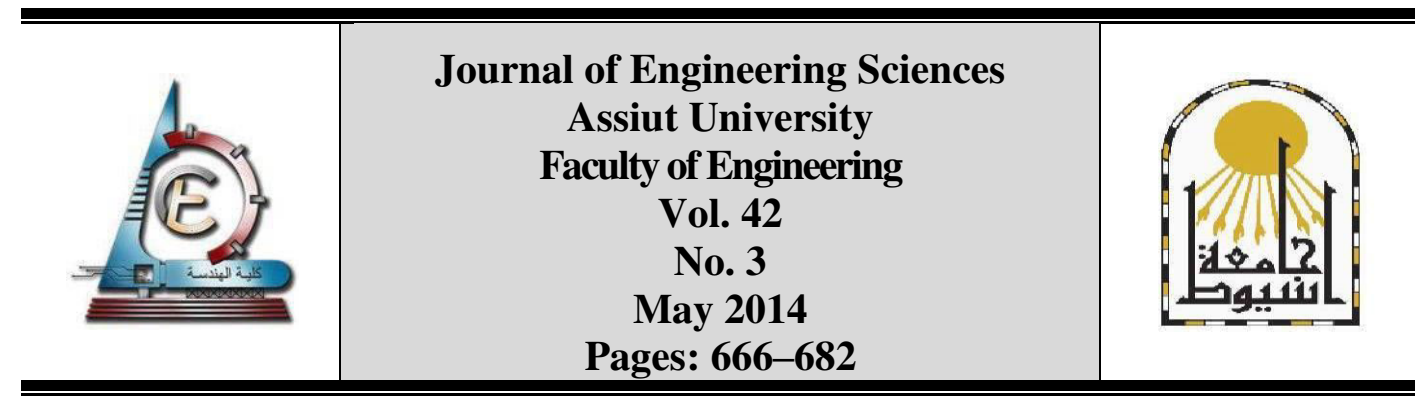

\title{
THE EFFECT OF USING FALSE CEILING ON ROOF COOLING LOAD
}

\author{
ALI H. Abdel Razek ${ }^{1,}$ *, Ibrahim S. Taha ${ }^{2}$, \\ Mahmoud G. Morsy ${ }^{3}$ and Ali K. Abdel-Rahman ${ }^{4}$ \\ ${ }^{1,2,3,4}$ Staff in mechanical Engineering Dept., Faculty of EngineeringAssiut University, 71516 Assiut
}

Received 15 January 2014; accepted 20 February 2014

\begin{abstract}
Using of false ceilings (FC) for decoration and covering different ducts in modern buildings is spreading so much nowadays. This paper tries to find a new employment and other benefits for using false ceilings (FC).A one dimensional transient mathematical model has been established to study the effects of using false ceiling on reduction of heat gained from concrete roof of controlled temperature space. The effect of using false ceiling (FC), with and without adding reflector sheet on its upper side facing to concrete roof on the room cooling load is studied by modeling and solving the transient heat transfer processes in the different components of the space. The results showed that using of false ceiling only without reflector sheet reduces heatgain introduced to space through 24 hours by $66.8 \%$, while using of false ceiling with reflector sheet increases the reduction percent of heat gained from concrete roof to be $81.6 \%$ for the same period.
\end{abstract}

Keywords: Concrete Roof; False Ceiling; Reflector Sheet; roof cooling load

\section{Introduction}

As fifty percent of external heat gain in the buildings is from the roof [1], therefore a lot of experimental and analytical studies all over the world had been performed to decrease that load. Removing of such load from buildings by active systems (like mechanical air conditioning systems) becomes very expensive specially with the fast spreading of energy crises around the world. Using of passive techniques to reduce buildings heat load have been very important. Using of materials of low conductance and heat capacitance, wind tower, and doomed roof were efficient methods. However such methods are difficult to be used in the high modern buildings. Most roofs nowadays are flat and made of high thermal capacitance material like concrete. So they need special methods to decrease their loads. Ciampi et al.[2] performed analytical study of tilted ventilated and micro ventilated roofs to investigate the reduction in summer thermal loads. They built their mathematical models of ventilated roof as turbulent flow model and for small thickness duct (micro ventilated roof) with laminar flow model. They studied two different roof designs. One of them was

* Corresponding author.

Email address:ali_hassan80@eng.au.edu.eg 
constructed from copper plate as upper slab and rigid fiberglass panel as lower slab, while the second one was constructed from a tile and wooden rafters as upper part with rigid fiberglass panel as lower part of the roof. They considered room temperature to have a constant value in all cases and presented one dimensional thermal energy balance model. They concluded that:

1. The roof having a tile as upper slab reduces heat gain comparing with the other of copper sheet.

2. Energy saving in the case of well-designed roof can be more than $30 \%$ with large duct height $(0.08 \mathrm{~m})$ and not exceeding $15 \%$ for micro ventilated design $(.04 \mathrm{~m})$.

3. Heat gain in case of closed duct is more than for open duct; so using roof design with closed duct is better in winter.

Biwole et al.[3] studied the effect of adding metallic screen sheet above sheet metal roof to make an inclined open channel to enhance natural convection over roof surface. They studied this double skin roof numerically by bi-dimensional numerical method and validated it by experimental work. The effect of thermal radiation properties of the roof components like emittance and reflectance on temperature profile was investigated for different channel cross-sections. They concluded that, there is enhancement in natural ventilation by increasing tilted angle and cavity width. But these factors did not have great effects on thermal radiation comparing with emittance reduction of sheet metal. They found a reduction of heat gain by about $58 \%$ when emittance of all components was reduced from 0.8 to 0.15 . Fracastoro et al.[4], presented a steady state analytical model to study reduction of heat gain by using under roof air cavities, for both opened (ventilated) and closed (unventilated) ones. They found that ventilated roofs may lead to a reduction up to fifty percentof the load for closed air cavity roofs.

This paper aims to study the effect of different parameters of false ceiling (FC) on the roof load. The false ceiling is usually used to cover ducts or pipes passed under roof, and become a part of the internal decoration of buildings. The objective of this work is to study the influence of false ceiling on heat load coming from concrete roof facing the sky by one dimensional transient model. In this work space temperature is controlled and the walls are completely insulated. So only heat gain will come from roof .Theoretical model used will treat three cases:

- Case one: Concrete roof only with no false ceiling (FC)

- Case two: Concrete roof with false ceiling (FC) making a closed cavity

- Case three: The pervious case but using reflector sheet(FC-R) on the upper face of false ceiling which is facing the concrete roof.

\section{Theoretical model}

\subsection{System and assumptions}

Figure (1) shows the dimensions of the room that will be studied and the different heat flow rates. For the system shown in Fig.(1), the following assumptions are taken into consideration when dealing with energy balances on the various components of the system

1. Heat transfer through the concrete roof, which is considered to be flat and horizontal, is one dimensional.

2. Air gap (space between roof and false ceiling) is thermally treated as homogeneous gap with bulk temperature of Tav.

3. False ceiling is thermally treated as a lumped heat capacitance system.

4. Room space has a constant temperature of $\mathrm{T}_{\text {in }}$. 
5. All walls and floor of the room are thermally insulated and treated as one surface of temperature $\mathrm{Tw}$.

6. All room internal loads are neglected, only external load from roof is to be considered.

7. The thermal and physical properties of system components are considered to be constants.

8. The meteorological conditions are considered as those of Assiut city, Egypt.

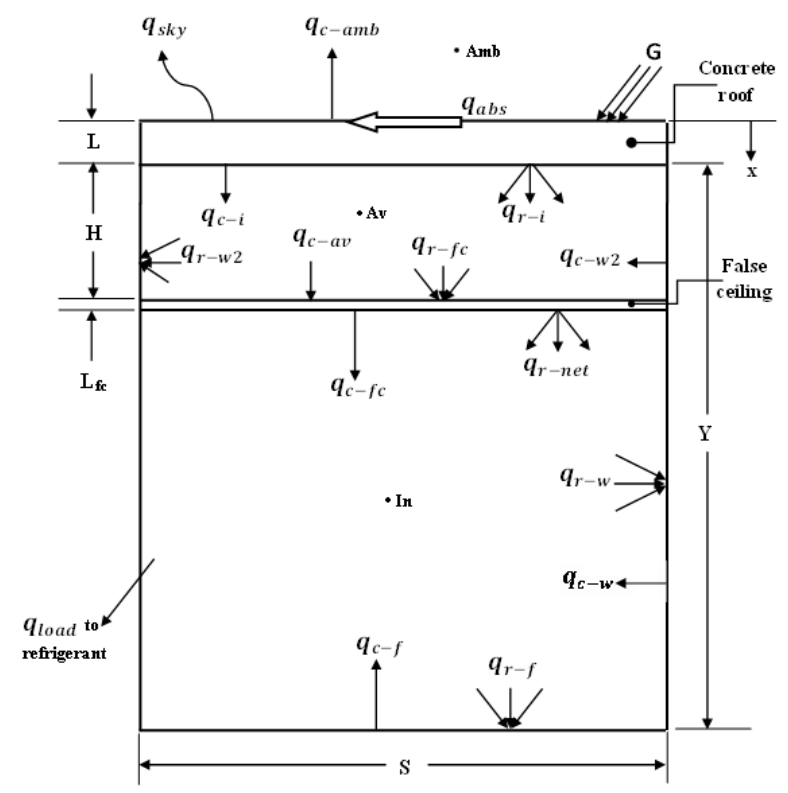

Fig. 1. Thermal model with different heat flow rates for the case of existence of FC.

\subsection{Analysis of roof slab}

By considering the roof to be a one dimensional slab of thickness $L$ with no heat generation, the heat flow through the roof maybe represented by one dimensional heat conduction equation[4]

$$
\frac{\partial T}{\partial t}=\alpha_{t h} \frac{\partial^{2} T}{\partial x^{2}}, \alpha_{t h}=\frac{k_{r}}{c_{r} \rho_{r}} \quad 0 \leq x \leq \mathrm{L}
$$

Where $\mathrm{T}$ is the roof temperature at any distance $\mathrm{x}$ and time $\mathrm{t}, \mathrm{k}_{\mathrm{r}}$ is the thermal conductivity of concrete roof $(\mathrm{W} / \mathrm{m} . \mathrm{K}), \mathrm{C}_{\mathrm{r}}$ is the specific heat of roof $(\mathrm{J} / \mathrm{kg} . \mathrm{K}), \rho_{r}$ is the concrete roof density $\left(\mathrm{kg} / \mathrm{m}^{3}\right), \alpha_{t h}$ is the thermal diffusivity of roof $\left(\mathrm{m}^{2} / \mathrm{s}\right)$, and $\mathrm{x}$ is the downward distance from the upper surface of the roof. The roof is exposed to convection and radiation on both sides.

Boundary condition of roof at the outer surface where $x=0.0$ is given by;

$-\left.k_{r} A_{c} \frac{\partial T}{\partial x}\right|_{x=0.0}=q_{a b s}-q_{c-a m b}-q_{s k y}$

The absorbed energy rate of incident solar radiation $q_{a b s}$ is calculated from the relation:

$q_{a b s}=A_{c} \alpha_{r} G$

Where $\mathrm{G}$ is calculated for clear sky model as follows[5];

$\mathrm{G}=\mathrm{I}_{\mathrm{b}} \cos \boldsymbol{\theta}_{\mathrm{z}}+\mathrm{D}$ 
The convective heat transfer between roof and ambient air $q_{c-a m b}$ is calculated from the relation;

$$
q_{c-a m b}=h_{o} A_{c}\left(T_{o}-T_{a m b}\right)
$$

and the convective heat transfer coefficient at the outer side of concrete roof is calculated from the relation[6]

$$
h_{o}=2.8+3.0 U_{\infty}
$$

Where $U_{\infty}$ is the wind velocity in $\mathrm{m} / \mathrm{s}$. The value of $U_{\infty}$ in Assiut town, Egypt is usually between $1.5-3.0 \mathrm{~m} / \mathrm{s}$ around year.

Ambient temperature $\mathrm{T}_{\mathrm{amb}}$ and sky temperature $\mathrm{T}_{\text {sky }}$ are calculated by the relations[5]

$$
\begin{aligned}
& T_{a m b}=\frac{T_{\max }+T_{\min }}{2}+\left(\frac{T_{\max -T_{\min }}}{2}\right) \sin \left[\frac{2 \pi}{24}(\tau-9)\right] \\
& T_{s k y}=0.0552 T_{a m b}^{1.5}, T_{a m b} \text { and } T_{s k y} \text { are in } \mathrm{K} .
\end{aligned}
$$

Where, $\mathrm{T}_{\max }$ and $\mathrm{T}_{\min }$ are the day maximum and minimum temperatures and $\tau$ is the time in hours measured from midnight. The radiation heat transfer to sky $q_{s k y}$ can be calculated by the relation:

$$
q_{s k y}=\varepsilon_{r} \sigma A_{c}\left(T_{o}^{4}-T_{s k y}^{4}\right), T_{o} \text { and } T_{s k y} \text { are in } \mathrm{K}
$$

Boundary condition at the inner surface $x=L$ is given by:

$$
-\left.k_{r} A_{c} \frac{\partial T}{\partial x}\right|_{x=L}=q_{c-i}+q_{r-i}
$$

In the previous equation (10), terms $q_{c r-a}$ and $q_{r-i}$ are differed according to the existence or absence of false ceiling; so the values of the two terms will be introduced separately.

When using false ceiling, the convection heat transfer rate between roof and downward air $q_{c-i}$ will be computed using the relation,

$$
q_{c-i}=h_{i} A_{c}\left(T_{i}-T_{a v}\right)
$$

The convective heat transfer coefficient at the roof inner surface $h_{i}$ is taken as free convection heat transfer coefficient with hot horizontal surface is at the top, and can be calculated by the relation[4]

$$
h_{i}=0.27\left[\frac{k_{a}^{3} \rho_{a} g C_{a}\left(T_{i}-T_{a v}\right)}{L_{c} v_{a} T_{f}}\right]^{\frac{1}{4}}
$$

Where $\mathrm{L}_{\mathrm{c}}$ is the ratio ofarea of the bottom surface of the slab to its perimeter,

$T_{f}=\frac{T_{i}+T_{a v}}{2}, T_{i}$ and $T_{a v}$ are in $\mathrm{K}$.

On the other hand, the term $q_{c-i}$ is calculated in the absence of false ceiling according to the relation,

$$
q_{c-i}=h_{i} A_{c}\left(T_{i}-T_{i n}\right)
$$

Where,

$$
h_{i}=0.27\left[\frac{k_{a}^{3} \rho_{a} g C_{a}\left(T_{i}-T_{i n}\right)}{L_{c} v_{a} T_{f}}\right]^{\frac{1}{4}} \text { and } T_{f}=\frac{T_{i}+T_{i n}}{2}, \mathrm{~T}_{\mathrm{f}} \text { is in } \mathrm{K}
$$

The net radiation heat transfer rate between inner roof surface and inside surfaces $q_{r-i}$ will differ according to the existence or absence of false ceiling. In the case of absence false ceiling, the value of $q_{r-i}$ will be computed by using the radiation network shown in Fig. (2). 


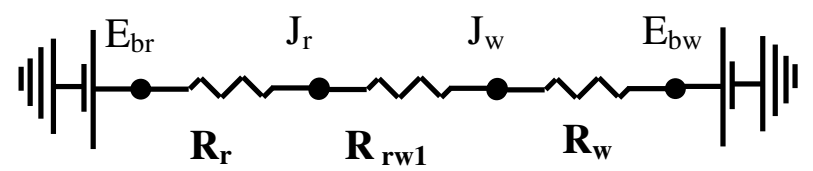

Fig. 2 Radiation network between concrete roof and room walls with no FC.

Where: $E_{b r}$ and $E_{b w 1}$ are the black body emissive flux for roof surface and walls and floor, while $\mathrm{J}_{\mathrm{r}}$ and $\mathrm{J}_{\mathrm{w} 1}$ are the radiosites for the same two surfaces respectively. Also $\mathrm{R}_{\mathrm{r}}$ and $R_{\mathrm{w} 1}$ are the surface resistances for roof surface and walls respectively, while $R_{\mathrm{rw} 1}$ is the geometrical resistance between inside roof surface and room walls and floor.

The different resistances shown in Fig.(2) are calculated as follows;

$$
R_{r}=\frac{1-\epsilon_{r}}{A_{c} \epsilon_{r}} \quad, R_{w 1}=\frac{1-\epsilon_{w}}{A_{w 1} \epsilon_{w}} \quad, R_{r w 1}=\frac{1}{A_{c} F_{r w 1}}
$$

$F_{r w 1}$ is the viewfactor between roof surface and inside room walls and floor, and it equals unity.

$$
A_{c}=S * Z \quad, A_{w 1}=2 \mathrm{Y} * \mathrm{Z}+2 \mathrm{Y} * S+(S * Z) \text {, see Fig.(1) }
$$

where $Z$ is the depth of the room in $(\mathrm{m})$.

$$
\begin{aligned}
& \text { Let, } \sum R_{r r-w}=R_{r}+R_{r w 1}+R_{w 1} \\
& q_{r-i}=\frac{\left(E_{b r}-E_{b w 1}\right)}{\sum R_{r r-w}}=\frac{\sigma\left(T_{i}^{4}-T_{w}^{4}\right)}{\sum R_{r r-w}}
\end{aligned}
$$

When installing the false ceiling, the radiation network between inner roof surface ,false ceiling upper surface, and the air gap's surrounding walls will be as shown in Fig.(3).

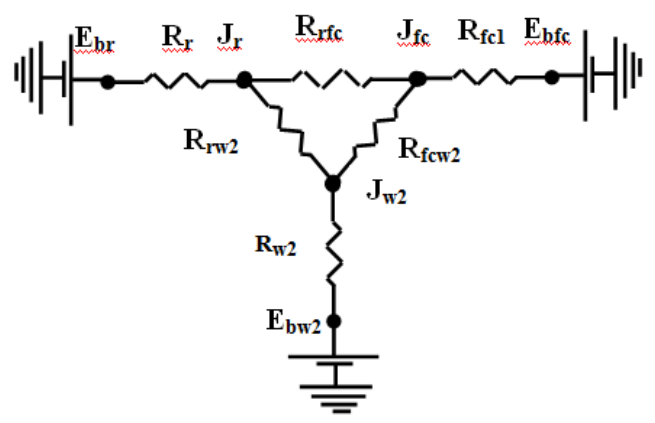

Fig. 3.Radiation network between concrete roofand inside surfaces of air gap's surrounding walls.

In this case the net radiation for inner roof surface is computed by the relation:

$$
\mathrm{q}_{\mathrm{r}-\mathrm{i}}=\frac{\left(E_{b r}-J_{r}\right)}{R_{r}}
$$

By making balance at every radio site node the values of different radio sites $\mathrm{J}_{\mathrm{r}}, \mathrm{J}_{\mathrm{fc}}$, and $\mathrm{J}_{\mathrm{w} 2}$ are obtainedas functions of temperatures.

$$
\begin{aligned}
& \frac{\left(E_{b r}-J_{r}\right)}{R_{r}}+\frac{\left(J_{w 2}-J_{r}\right)}{R_{r w 2}}+\frac{\left(J_{f c}-J_{r}\right)}{R_{r f c}}=0.0 \\
& \frac{\left(E_{b f c}-J_{f c}\right)}{R_{f c 1}}+\frac{\left(J_{r}-J_{f c}\right)}{R_{r f c}}+\frac{\left(J_{w 2}-J_{f c}\right)}{R_{f c w 2}}=0.0
\end{aligned}
$$




$$
\frac{\left(E_{b w 2}-J_{w 2}\right)}{R_{w 2}}+\frac{\left(J_{r}-J_{w 2}\right)}{R_{r w 2}}+\frac{\left(J_{f c}-J_{w 2}\right)}{R_{f c w 2}}=0.0
$$

For Fig. (3), the values of different resistances can be computed as given below:

$$
\begin{aligned}
& R_{r}=\frac{1-\epsilon_{r}}{A_{c} \epsilon_{r}} \quad, R_{f c 1}=\frac{1-\epsilon_{f c 1}}{A_{c} \epsilon_{f c 1}} \quad, R_{r w 2}=\frac{1}{A_{c} F_{r w 2}}, R_{w 2}=\frac{1-\epsilon_{w}}{A_{w 2} \epsilon_{w}} \\
& R_{f c w}=\frac{1}{A_{c} F_{f c w 2}}, R_{r f c}=\frac{1}{A_{c} F_{r f c}}, A_{w 2}=2 \mathrm{H} * \mathrm{Z}+2 \mathrm{H} * S
\end{aligned}
$$

The shape or view factors $F_{r f c}, F_{r w 2}$, and $F_{f c w 2}$ can be calculated by considering roof, false ceiling, and side walls form a rectangular parallel piped enclosure, and the equation used is as follow [4].

$$
F_{r f c}=\frac{2}{\pi S 1 Z 1}\left\{\begin{array}{c}
\ln \left[\frac{\left(1+S 1^{2}\right)\left(1+Z 1^{2}\right)}{1+S 1^{2}+Z 1^{2}}\right]^{\frac{1}{2}}+S 1\left(1+Z 1^{2}\right)^{\frac{1}{2}} \tan ^{-1} \frac{S 1}{\left(1+Z 1^{2}\right)^{\frac{1}{2}}} \\
+Z 1\left(1+S 1^{2}\right)^{\frac{1}{2}} \tan ^{-1} \frac{Z 1}{\left(1+S 1^{2}\right)^{\frac{1}{2}}} \\
-S 1 \tan ^{-1} S 1-Z 1 \tan ^{-1} Z 1
\end{array}\right\}
$$

Where $\mathrm{Z}$ is the depth of the room, $\mathrm{S} 1=\frac{\mathrm{S}}{\mathrm{H}}$, and $\mathrm{Z} 1=\frac{\mathrm{Z}}{\mathrm{H}}$

Also, $F_{r f c}=F_{f c r}, \quad F_{r w 2}=1-F_{r f c}$, and $F_{f c w 2}=F_{r w 2}$

\section{Initial condition of roof slab is considered to be:}

$\mathrm{T}(\mathrm{x}, 0)=\mathrm{T}_{\mathrm{amb}}(0)$

\subsection{Analysis of air gap}

As mentioned in the assumptions of model, the variation of air gap temperature $\left(\mathrm{T}_{\mathrm{av}}\right)$ across the gap height $\mathrm{H}$ is neglected, so only variation with time is to be considered. Figure(4) shows the heat transfer rates crossing the boundaries of air gap.

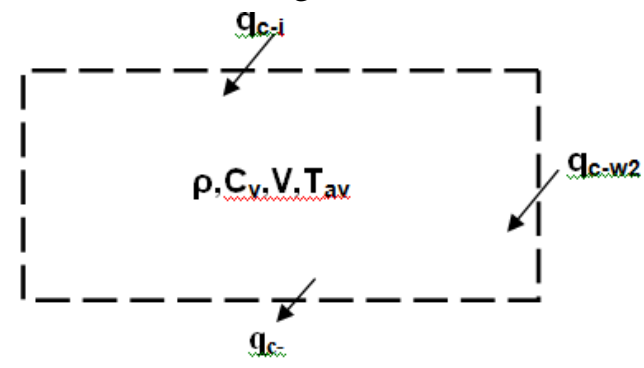

Fig. 4. Heat transfer rates crossing boundaries of air gap.

By applying first law of thermodynamics to air gap; the energy balance equation will be as follow;

$$
q_{c-i}-q_{c-a v}+q_{c-w 2}=\left(\rho_{a} C_{v} V_{g}\right) \frac{d T_{a v}}{d t}
$$

where,

$$
\begin{aligned}
& q_{c-a v}=h_{a v} A_{c}\left(T_{a v}-T_{f c}\right) \\
& h_{a v}=0.27\left[\frac{k_{a}^{3} \rho_{a} C_{a} g\left(\boldsymbol{T}_{a v}-T_{f c}\right)}{L_{c} v_{a} T_{f 2}}\right]^{\frac{1}{4}}, T_{f 2}=\frac{T_{a v}+T_{f c}}{2} ; \mathrm{T}_{\mathrm{av}} \text { and } \mathrm{T}_{\mathrm{fc}} \text { are in } \mathrm{K} .
\end{aligned}
$$


$q_{c-w 2}=h_{w 2} A_{w 2}\left(T_{w 2}-T_{a v}\right)$

$h_{w 2}=\frac{k}{H}\left[0.825+\frac{0.387 R_{a l}^{\frac{1}{6}}}{\left[1+\left(\frac{0.492}{P_{r}}\right)^{\frac{9}{16}}\right]^{8 / 27}}\right]^{2}$ for vertical walls[4].

where,

$R_{a l}=\frac{g \beta\left(T_{w 2}-T_{a v}\right) L_{c}^{3}}{\gamma \alpha}$ and $\frac{1}{\beta}=\frac{T_{w 2}+T_{a v}}{2}, \mathrm{~T}_{\mathrm{w} 2}$ and $\mathrm{T}_{\mathrm{av}}$ are in $\mathrm{K}, \mathrm{L}_{\mathrm{c}}=\mathrm{H}$.

Hence; $h_{w 2}=\frac{k}{H}\left[0.825+\frac{0.4344\left(\frac{g(H)^{3}}{\gamma \alpha}\right)^{\frac{1}{6}}}{\left[1+\left(\frac{0.492}{P_{r}}\right)^{\frac{9}{16}}\right]^{8 / 27}}\left(\frac{T_{w 2}-T_{a v}}{T_{w 2}+T_{a v}}\right)^{\frac{1}{6}}\right]^{2}$

Initial condition for air gap is considered as follow:-

$\mathrm{T}_{\mathrm{av}}(0)=\mathrm{T}_{\mathrm{amb}}(0)$

2.4. Analysis of air gap's walls

The energy balance equation for walls surrounding the air gap is as follow;

$\frac{J_{w 2}-E_{b w 2}}{A_{w 2} R_{w 2}}=h_{w 2} A_{w 2}\left(T_{w 2}-T_{a v}\right)$

\section{Initial condition for air gap's wall:}

$\mathrm{T}_{\mathrm{w} 2}(0)=\mathrm{T}_{\mathrm{amb}}(0)$

2.5. Analysis of false ceiling

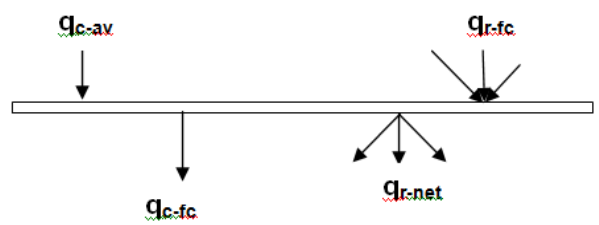

Fig. 5. Heat transfer rates crossing boundaries of false ceiling

Referring to Fig.(5) and applying first law of thermodynamics to false ceiling, the energy balance equation will be in the form;

$$
\begin{aligned}
& q_{c-a v}+q_{r-f c}-q_{c-f c}-q_{r-n e t}=(\rho C V)_{f c} \frac{d T_{f c}}{d t} \\
& q_{r-f c}=\frac{\left(J_{f c}-E_{b f c}\right)}{R_{f c 1}} \\
& q_{c-f c}=h_{f c} A_{c}\left(T_{f c}-T_{i n}\right) \\
& h_{f c}=0.27\left[\frac{k_{a}^{3} \rho_{a} C_{a} g\left(T_{f c}-T_{i n}\right)}{L_{c} v_{a} T_{f 3}}\right]^{\frac{1}{4}} \text { and } T_{f 3}=\frac{T_{f c}+T_{i n}}{2}, \mathrm{~T}_{\mathrm{fc}} \text { and } \mathrm{T}_{\text {in }} \text { are in } \mathrm{K} .
\end{aligned}
$$

Figure 6 shows the radiation network by consideringthe lower surface of FC and room walls and floor which form room space as two surfaces enclosure. 


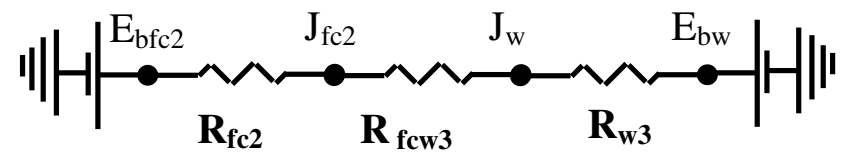

Fig. 6. Radiation network between false ceiling and room walls

Where: $\mathrm{E}_{\mathrm{bfc} 2}$ and $\mathrm{E}_{\mathrm{bw} 3}$ are the black body emissive flux for lower surface of FC and inside surface of room walls and floor, while $\mathrm{J}_{\mathrm{fc} 2}$ and $\mathrm{J}_{\mathrm{w} 3}$ are the radiosites for the same two surfaces respectively. Also, $\mathrm{R}_{\mathrm{fc} 2}$ and $\mathrm{R}_{\mathrm{w} 3}$ are the surface resistances for lower surface of FC and inside surface of room walls respectively, while $R_{\mathrm{fcw} 3}$ is the geometrical resistance between inside roof surface and room walls and floor.

$R_{w 3}=\frac{1-\epsilon_{w}}{A_{w 3} \epsilon_{w}} \quad, R_{f c 2}=\frac{1-\epsilon_{f c 2}}{A_{c} \epsilon_{f c 2}} \quad, R_{f c w 3}=\frac{1}{A_{c} F_{f c w 3}}, F_{f c w 3}=1$

$\sum \mathrm{R}_{\mathrm{rfc}-\mathrm{w}}=\mathrm{R}_{\mathrm{fc} 2}+\mathrm{R}_{\mathrm{fcw} 3}+\mathrm{R}_{\mathrm{w} 3}$

where $A_{w 3}=2\left(\mathrm{Y}-\mathrm{H}-\mathrm{L}_{\mathrm{fc}}\right) * \mathrm{Z}+2\left(\mathrm{Y}-\mathrm{H}-\mathrm{L}_{\mathrm{fc}}\right) * S+(S * Z)$

$q_{r-n e t}=\frac{\sigma\left(T_{f c 2}^{4}-T_{w}^{4}\right)}{\sum R_{r f c-w}}, \mathrm{~T}_{\mathrm{fc} 2}$ and $\mathrm{T}_{\mathrm{w}}$ are in $\mathrm{K}$.

Initial condition for false ceiling is taken as follow:

$\mathrm{T}_{\mathrm{fc}}(0)=\mathrm{T}_{\mathrm{amb}}(0)$

2.6. Analysis of room walls and floor

When using false ceiling, theenergy balance on the walls and floor surfaces is as follow,

$q_{r-n e t}=q_{c-w}+q_{c-f}$

where $q_{c-w}$ is the convection heat transfer rate between walls and air inside room space and is calculated by the following relation

$q_{c-w}=h_{w} A_{w 4}\left(T_{w}-T_{i n}\right)$

where $A_{w 4}=2\left(\mathrm{Y}-\mathrm{H}-\mathrm{L}_{\mathrm{fc}}\right) * \mathrm{Z}+2\left(\mathrm{Y}-\mathrm{H}-\mathrm{L}_{\mathrm{fc}}\right) * S$

and the free convective heat transfer between room walls and air inside room $h_{w}$ is calculated by the relations[4],

$$
h_{w}=\frac{k}{Y-H-L_{f c}}\left[0.825+\frac{0.387 R_{a l}^{\frac{1}{6}}}{\left[1+\left(\frac{0.492}{P_{r}}\right)^{\frac{9}{16}}\right]^{8 / 27}}\right]^{2}
$$

$R_{a l}=\frac{g \beta\left(T_{w}-T_{\text {in }}\right) L_{C}^{3}}{\gamma \alpha}$ and $\frac{1}{\beta}=\frac{T_{w}+T_{\text {in }}}{2}, \mathrm{~T}_{\mathrm{w}}$ and $\mathrm{T}_{\mathrm{in}}$ are in $\mathrm{K}$.

So, $h_{w}=\frac{k}{Y-H-L_{f c}}\left[0.825+\frac{0.4344\left(\frac{g(Y-H)^{3}}{\gamma \alpha}\right)^{\frac{1}{6}}}{\left[1+\left(\frac{0.492}{P_{r}}\right)^{\frac{9}{16}}\right]^{8 / 27}}\left(\frac{T_{w}-T_{i n}}{T_{w}+T_{i n}}\right)^{\frac{1}{6}}\right]^{2}$

While $q_{c-f}$ is the convection heat rate between floor and air inside room space, and is calculated by the following relation; 


$$
\begin{aligned}
& q_{c-f}=h_{f} A_{c}\left(T_{w}-T_{i n}\right) \\
& \text { Where }_{f}=0.27\left[\frac{k_{a}^{3} \rho_{a} C_{a} g\left(T_{w}-T_{i n}\right)}{L_{c} v_{a} T_{f 4}}\right]^{\frac{1}{4}} \text { and } T_{f 4}=\frac{T_{w}+T_{\text {in }}}{2}
\end{aligned}
$$

In the absence of false ceiling, the energy balance equation on the walls and floor surfaces will be as follows,

$$
\begin{aligned}
& q_{r-i}=q_{c-w}+q_{c-f} \\
& \therefore \frac{\sigma\left(T_{i}^{4}-T_{w}^{4}\right)}{\sum R_{e r-w}}=h_{w} A_{w 5}\left(T_{w}-T_{i n}\right)+h_{f} A_{c}\left(T_{w}-T_{i n}\right)
\end{aligned}
$$

From Fig.(2): $\sum R_{\text {er }-w}=R_{r}+R_{r w 1}+R_{w 1}$

The value of $h_{w}$ in equation (45) will differ from the same coefficient in equation (41) because the walls height is changed. So $h_{w}$ of equation (45) is obtained from the following relation:

$$
h_{w}=\frac{k}{Y}\left[0.825+\frac{0.4344\left(\frac{g(Y)^{3}}{\gamma \alpha}\right)^{\frac{1}{6}}}{\left[1+\left(\frac{0.492}{P_{r}}\right)^{\frac{9}{16}}\right]^{8 / 27}}\left(\frac{T_{w}-T_{i n}}{T_{w}+T_{i n}}\right)^{\frac{1}{6}}\right]^{2}
$$

while $A_{w 5}=2 \mathrm{Y} * \mathrm{Z}+2 \mathrm{Y} * S$

\subsection{Analysis of room air}

As stated before, the temperature of room air is assumed to be controlled at a constant value $T_{\text {in }}$. The energy balance equation in the absence of false ceiling is given by:

$$
q_{\text {load }}=q_{c-i}+q_{c-w}+q_{c-f}
$$

Where $q_{\text {load }}$ is the cooling load delivered out by refrigerating machine, and when using false ceiling, the energy balance equation will be in the form

$$
q_{\text {load }}=q_{c-f c}+q_{c-w}+q_{c-f}
$$

\section{Method of solution}

In this model there is a set of unknowns which are to be obtained to estimate different heat transfer rates in the model. These unknowns are roof temperature $T(x, t)$, air gap temperature $T_{a v}(t)$, air gap's walls temperature $T_{w 2}$, false ceiling temperature $T_{f c}(t)$, and room walls temperature $\mathrm{T}_{\mathrm{w}}(\mathrm{t})$.

The governing equations of the system components (roof, air gap, air gap's walls, false ceiling, and space walls and floor) are simultaneous partial and ordinary differential equations and algebraic equations. Because the boundary conditions are time dependent, there is no available closed form solution for such equations. The time duration of one day is discretized into time interval each of one hour.

The following steps are followed to obtain the solution at the end of each time interval.

1. The time interval for solution $\Delta \mathrm{t}=3600 \mathrm{~s}$.

2. The roof slab is divided into $m$ (15) elements with the upper and lower elements are having half the thickness of the element. Equation (1) is applied to the interior elements, while the boundary equations $(2,10)$ are applied to the upper and lower elements respectively. 
3. The differential terms are discretized using a finite difference scheme.

4. Guessed values for the gap's air, air gap's surrounding walls, and false ceiling temperatures are used to determine the temperatures of the roof elements (values at starting time are used).

5. The gap air temperature $T_{a v}$, and false ceiling temperature $T_{\mathrm{fc}}$ are obtained using equations $(23,32)$ by applying the $4^{\text {th }}$ order Runge-Kutta technique using the results of the ceiling temperatures as well as the guessed value of space walls and floor temperature.

6. The air gap's surrounding walls is thus obtained using equation (30).

7. The space walls and floor temperature is thus obtained using equation (38).

8. Multiple iteration loops are then applied through Fortran code to obtain the solution for the temperatures of all components at the end of the time interval.

9. The procedure given above is repeated for all time intervals to cover the whole day.

\subsection{Model dimensions and thermophysical properties of its material}

The dimensions used in this analysis are given in table 1. Zach et al.[7] presented an empirical study to evaluate thermal conductivity of lightweight concrete. The density and thermal conductivity of roof material were determined from [7]. Thermal radiation properties as solar absorbance and long wave emittance were obtained from[8]. Infrared emittance of wall and AL foil used as reflector sheet on false ceiling were taken from[9], while properties of false ceiling (density, specific heat, and thermal conductivity) were taken from a specification sheet of commercial false ceiling board. The properties used in this analysis are given in Table 2.

\section{Table 1.}

Dimensions of model

\begin{tabular}{|l|l|l|l|l|l|l|}
\hline Dimension & $\mathbf{L}$ & $\mathbf{H}$ & $\mathbf{L}_{\mathbf{f c}}$ & $\mathbf{Y}$ & $\mathbf{S}$ & $\mathbf{Z}$ \\
\hline Value $(\mathrm{m})$ & 0.12 & 0.60 & 0.01 & 3.0 & 3.0 & 2.0 \\
\hline
\end{tabular}

Table 2.

Properties of selected materials

\begin{tabular}{|l|c|c|c|c|c|}
\hline material & Density $\left(\mathbf{k g} / \mathbf{m}^{\mathbf{3}}\right)$ & $\mathbf{C}_{\mathbf{p}}(\mathbf{J} / \mathbf{k g} \cdot \mathbf{K})$ & $\mathbf{k}(\mathbf{W} / \mathbf{m} . \mathbf{K})$ & Emittance & Absorbtance \\
\hline Concrete Roof & 2300 & 1000 & 0.4118 & 0.9 & 0.8 \\
\hline False Ceiling & 600 & 1090 & 0.191 & 0.8 & - \\
\hline Reflector & - & - & - & 0.09 & - \\
\hline Walls & - & - & - & 0.96 & - \\
\hline Air & 1.205 & 1005 & 0.0257 & - & - \\
\hline
\end{tabular}

\subsection{Validation of theoretical model}

This model has been solved using meteorological data conditions for Assiut city, Egypt $\left(27.11^{\mathrm{o}}\right.$ north, $30.04^{\mathrm{o}}$ east) in summer seasonon $21^{\mathrm{st}}$ June. The maximum and minimum temperatures are $43^{\circ} \mathrm{C}$ and $26^{\circ} \mathrm{C}$ respectively and constant indoor temperature $\mathrm{T}_{\text {in }}$ equal $20^{\circ} \mathrm{C}$. The present computer code was validated by comparing numerical results with experimental results published byJo et al.[10].The described conditions in [10] included site (Phoenix, Arizona, USA $33.34^{\circ}$ north and longitude $112.06^{\circ}$ west), climatic conditions, and indoor air conditions were taken in consideration and adopted in the computer code for comparing of results. The comparison was made for the outer surface temperature of an 
ordinary roof (which has symbol B in [10]) having no thermal reating. Figure (7) shows the differences between theoretical results of case one and experimental data taken from [10].

The correlation coefficient between experimental data and theoretical results is 0.98 and standard error is 2.23 . So a good agreement has been achieved by the model.

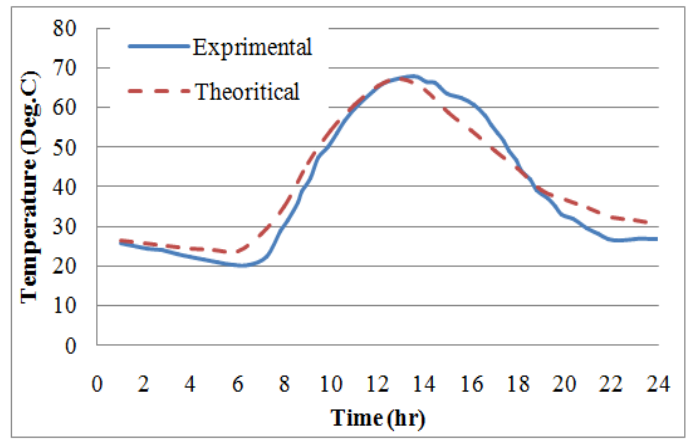

Fig. 7.Variation of experimental data of [10] and theoretical results of outside roof surface temperaturesduring day time for case one (no FC)

\section{Results and discussion}

Figure 8 shows the hourly variation obtained for ambient temperature and solar radiation on roof surface.

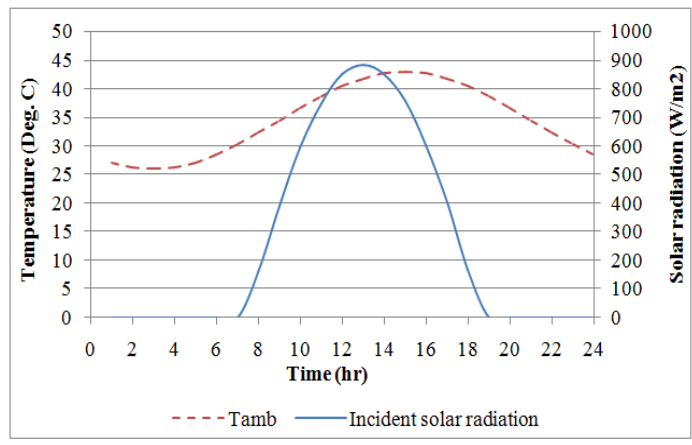

Fig. 8. Variation of total incident solar radiation and ambient temperature through day time (Assiut, June 21 ${ }^{\text {st }}$ )

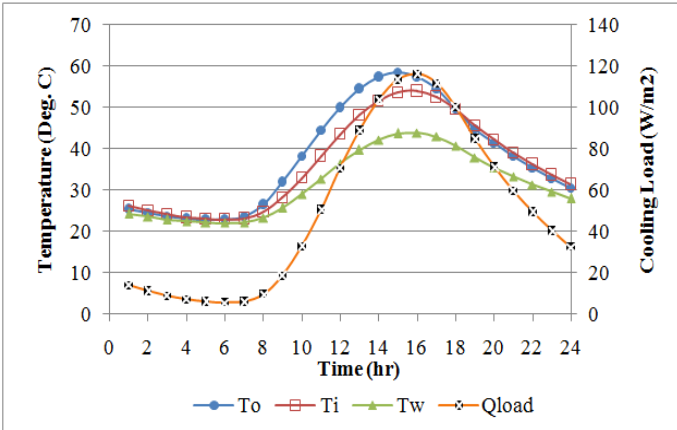

Fig. 9.Variation of temperatures and roof cooling load for case one of the model (no FC) 
Figure 9 shows thedaily variation of temperatures for walls, outer and inner roof surface and also shows the daily variation of roof cooling load for case one (Concrete roof only with no FC). Due to thermal storage characteristics of concrete roof, there is a difference between maximum temperature at the inner and outer roof surfaces. The temperature of wall and inner roof surface reach to their maximum value at the same time because the wall gained heat only by radiation exchange with inner surface of the roof. The slight increase of inner roof surface temperatures above temperatures of outer surface at the beginning and ending of day time occurs due to increasing of heat loss from outer surface to adjacent air by convection and to deep sky by radiation. The cooling load and inner surface temperature of the roof reach to their maximum and minimum values at the same time because the roof cooling load is a summation of radiation and convection load coming from inner surface of the roof.

The effects of using false ceiling -without reflector- under flat concrete roof (case two) on temperatures of model components are shown in Fig. (10). The Temperature of outer and inner surfaces of the roof has been increased compared with their value in the first case, while the temperature of wall is decreased. Also the temperature of FC is lower than the temperature of inner surface of the roof. These results lead to increased losses out from roof to ambient and decreased heat gain introduced to room space.

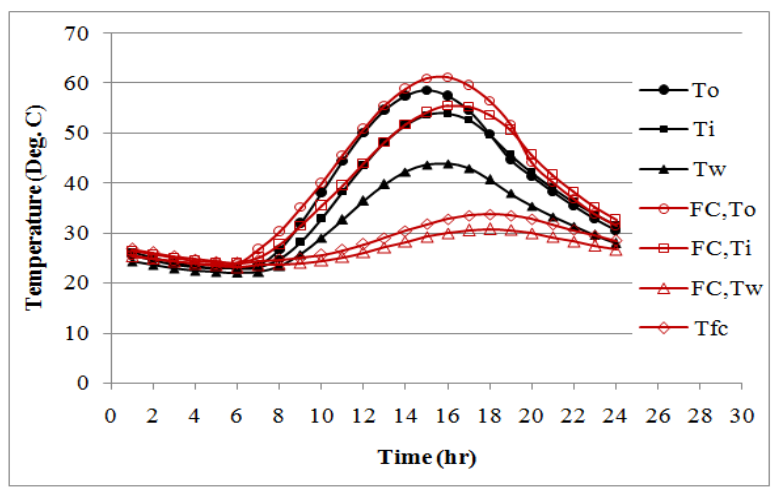

Fig. 10. Variation of temperatures with time for first and second cases of the model

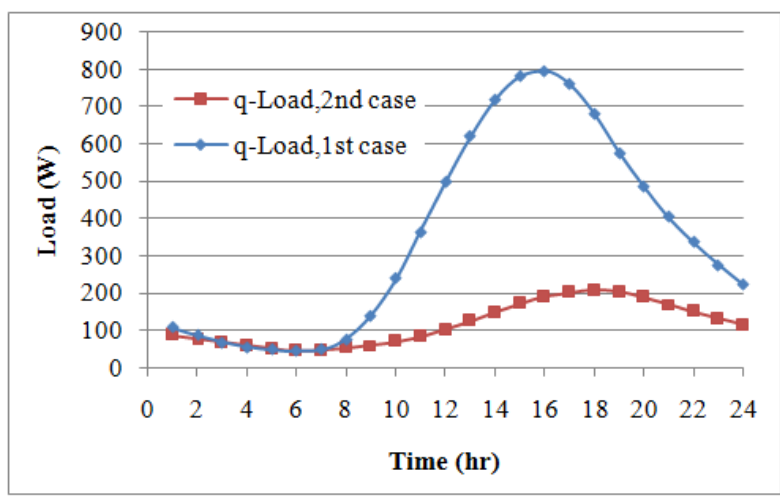

Fig. 11. Variation of cooling load with time for cases one and two of the model

Figure (11) shows the cooling load for the first and second cases. The cooling load (qLoad) is reduced when using FC (case two) compared with cooling load without using of FC (case one). False ceiling in this case works as a radiation shield and prevented a large amount of radiation load to pass from roof to room walls. At the same time it decreases the convection load to the space. From 
definition of radiation shield published in [11], the effectiveness of radiation shield will be increased if emittance of its surface is low. So, pasting of a reflector sheet having a much lower emittance than the FC on the upper side facing concrete roof is expected to increase its effectiveness.

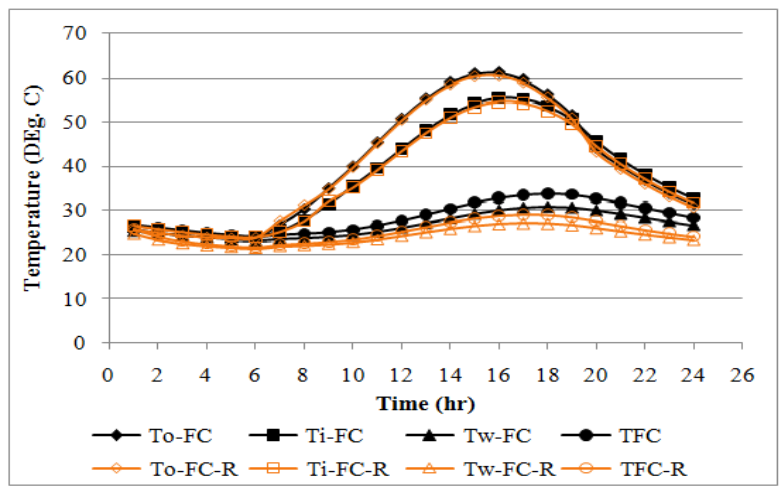

Fig. 12. Variation of temperatures with time for second and third cases of the model

Figure (12) shows the variation of temperatures with time by using false ceiling with reflector sheet (FC-R). As seen in Fig. (12), the influence of using reflector sheet on reducing temperatures of $\mathrm{FC}$ and walls is obvious.So, as known from governing equations, the cooling load will be reduced too.

Figure (13) showsthe cooling loads (qLoad) in the third case compared with thesecond case of the model. It indicates a reduction in maximum load in the case three (comparing with case two) by about (41\%). Figure (14) shows a comparison between total energy gained by the space in the three cases of the model during one day (June $21^{\text {st }}$, Assiut).

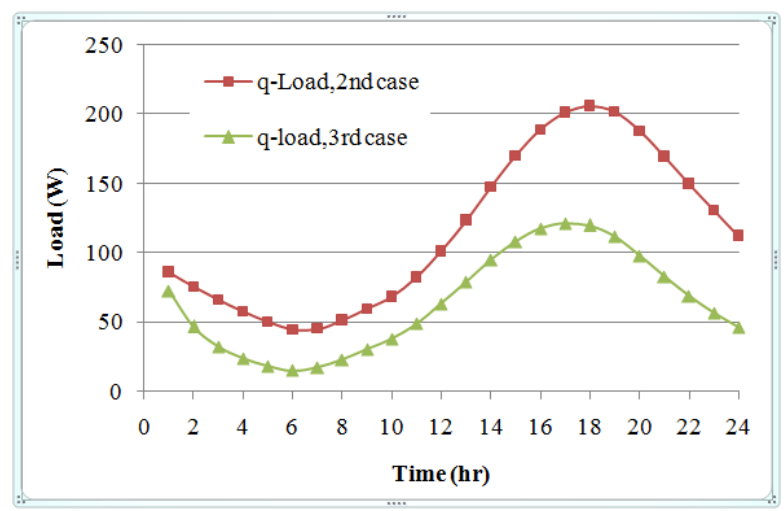

Fig. 13. Variation of cooling load for second and third cases of the model 


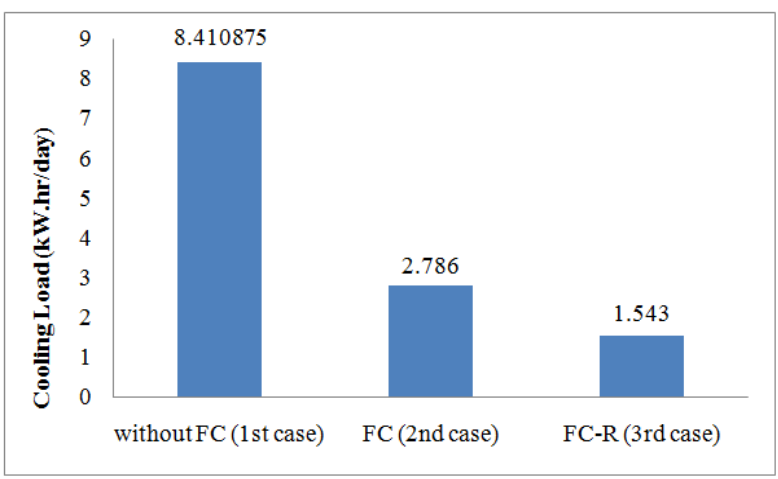

Fig. 14. Total energy gained by the space for the three cases during one day

Referring to Fig.(14), the energy saving due to installation of FC under concrete roof is about $66.8 \%$ and it increase to about $81.6 \%$ when using reflector sheet with FC.

\section{Conclusions}

In this paper, transient temperature distribution for different components of ( $3 \mathrm{~m} \times 3 \mathrm{~m} \times 2 \mathrm{~m})$ room with flat horizontal concrete roof, false ceiling, and walls as well as the resulting roof cooling load of space have been studied theoretically. A computational code based on theoretical solution of thermal model was used. The model has been adapted to three cases; first case is for the room with concrete roof only, the second case is when adding a FC under concrete roof, and the third case is when pasting a reflector sheet to the upper surface of the FC.

Results of the thermal model were obtained using meteorological conditions of Assiut town, Egypt $\left(27.11^{\circ}\right.$ north, $30.04^{\mathrm{o}}$ east $)$ one day of summer season $\left(21^{\mathrm{st}} \mathrm{June}\right)$ with constant indoor temperature equal $20{ }^{\circ} \mathrm{C}$. The present computer code was validated by comparing numerical results with experimental results published by Jo et al. [10] for the first case. It is concluded that using of false ceiling (FC) saves $66.8 \%$ of daily flat concrete roof cooling load of space. Also, when pasting reflector sheet to the upper surface of false ceiling (FC-R) the cooling load saving is about $81.6 \%$.

\section{Nomenclature}

$\begin{array}{ll}\mathrm{A}_{\mathrm{c}} & \text { Cross-section area of concrete roof }\left(\mathrm{m}^{2}\right) \\ \mathrm{A}_{\mathrm{w}} & \text { Surface area of room walls }\left(\mathrm{m}^{2}\right) \\ \mathrm{C}_{\mathrm{a}} & \text { Specific heat of air }(\mathrm{J} / \mathrm{kg} . \mathrm{K}) \\ \mathrm{C}_{\mathrm{r}} & \text { Specific heat of concrete roof }(\mathrm{J} / \mathrm{kg} . \mathrm{K}) \\ \mathrm{D} & \text { Diffused solar radiation flux }\left(\mathrm{W} / \mathrm{m}^{2}\right) \\ \mathrm{G} & \text { Total incident solar radiation flux }\left(\mathrm{W} / \mathrm{m}^{2}\right) \\ \mathrm{h}_{\mathrm{av}} & \text { Convection heat transfer coefficient between gab air and FC. }\left(\mathrm{W} / \mathrm{m}^{2} . \mathrm{K}\right) \\ \mathrm{h}_{\mathrm{f}} & \text { Convection heat transfer coefficient between floor and room air }\left(\mathrm{W} / \mathrm{m}^{2} . \mathrm{K}\right) \\ \mathrm{h}_{\mathrm{fc}} & \text { Convection heat transfer coefficient between FC. and room air }\left(\mathrm{W} / \mathrm{m}^{2} . \mathrm{K}\right) \\ \mathrm{h}_{\mathrm{i}} & \text { Convection heat transfer coefficient at inner surface of roof }\left(\mathrm{W} / \mathrm{m}^{2} . \mathrm{K}\right) \\ \mathrm{h}_{\mathrm{o}} & \text { Convection heat transfer coefficient at outer surface of roof }\left(\mathrm{W} / \mathrm{m}^{2} . \mathrm{K}\right) \\ \mathrm{h}_{\mathrm{w}} & \text { Convection heat transfer coefficient between walls and room air }\left(\mathrm{W} / \mathrm{m}^{2} . \mathrm{K}\right) \\ \mathrm{h}_{\mathrm{w} 2} & \text { Convection heat transfer coefficient between walls and gab air }\left(\mathrm{W} / \mathrm{m}^{2} . \mathrm{K}\right) \\ \mathrm{I}_{\mathrm{b}} & \text { Direct solar beam radiation flux on horizontal surface }\left(\mathrm{W} / \mathrm{m}^{2}\right) \\ \mathrm{k}_{\mathrm{a}} & \text { Thermal conductivity of air }(\mathrm{W} / \mathrm{m} . \mathrm{K})\end{array}$




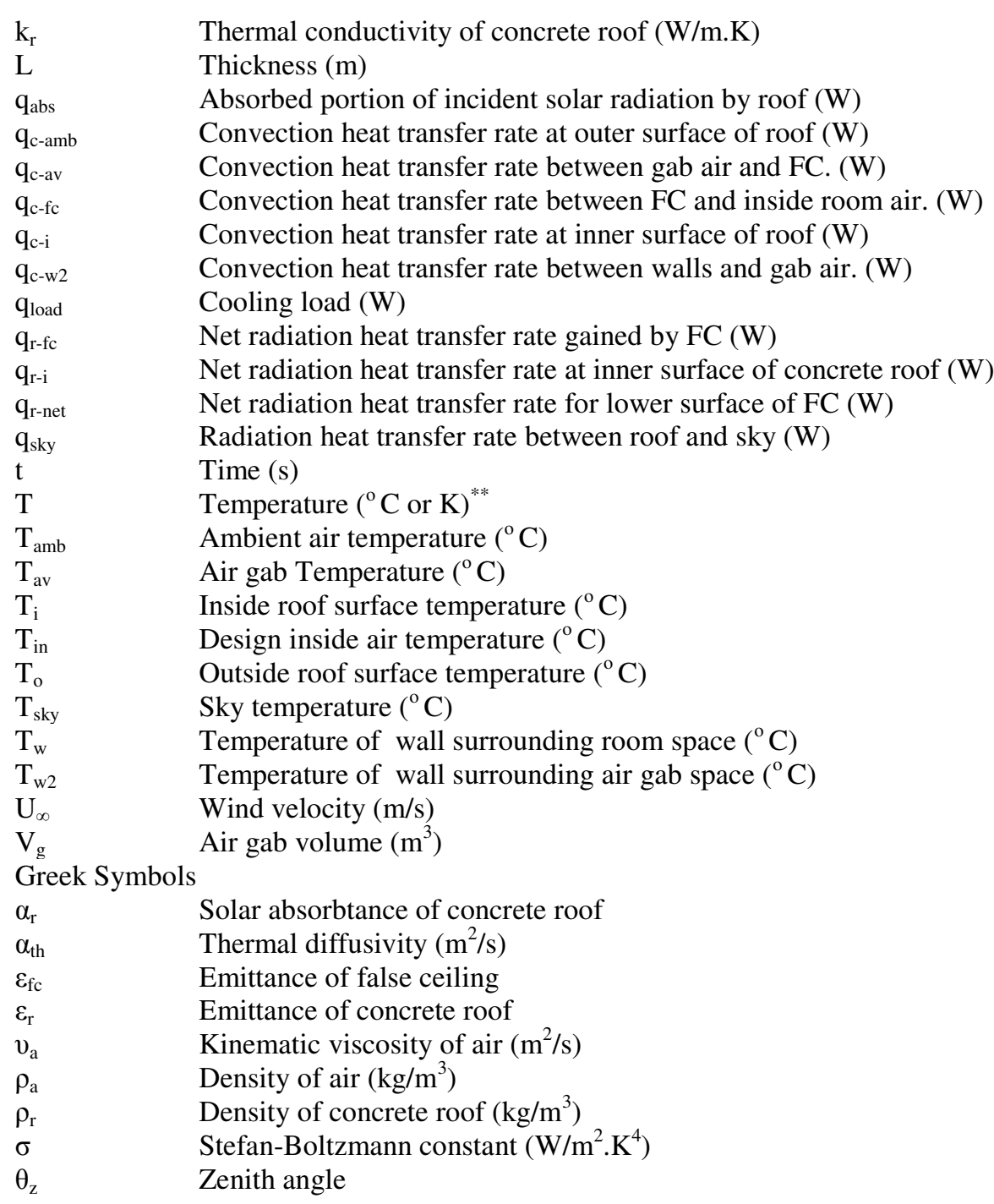

\section{REFERENCES}

[1] Ciampi, M., F. Leccese, and G. Tuoni, Energy analysis of ventilated and microventilated roofs. Solar Energy. 79(2): p. 183-192, 2005.

[2] Biwole, P., M. Woloszyn, and C. Pompeo, Heat transfers in a double-skin roof ventilated by natural convection in summer time. Energy and Buildings. 40(8): p. 1487-1497, 2008.

[3] Fracastoro, G., L. Giai, and M. Perino. Reducing cooling loads with under roof air cavities. Proceedings of AIVC 18th conference, "Ventilation and Cooling". Athhens, Greece, September 23-26, 1997.

[4] Incropera, F.P., A.S. Lavine, and D.P. DeWitt, Fundamentals of heat and mass transfer. John Wiley \& Sons Incorporated, 2011.

[5] Elsayed, M.M., I.S. Taha, and J.A. Sabbagh, Design of solar thermal systems. Jeddah, Saudi Arabia: Scientific Publishing Center, King Abdulaziz University. 1994.

[6] Duffie, J.A. and W.A. Beckman, Solar engineering of thermal processes. Third ed., New York, USA: John Wiley\& Sons Inc, 1980.

[7] Zach, J., M. Hubertova, and J. Hroudova. Possibilities of determination of thermal conductivity of lightweight concrete with utilization of non stationary hot-wire method. The 
10th international conference of the slovenian society for non-destructive testing, Ljubljana, Slovenia. Citeseer, 2009.

[8] Jain, A., A step towards urban building information modeling: measuring design and field variables for an urban heat island analysis, in Faculty of the School of Architecture South California,USA, 2009.

[9] Eicker, U., Low energy cooling for sustainable buildings. 1st ed., UK: John Wiley \& Sons, Ltd, 2009.

[10] J.H. Jo, J.D.C., J.S. Golden and H.B. , An integrated empirical and modeling methodology for analyzing solar reflective roof technologies on commercial buildings. Building and Environment. 45(2): p. 453-460, 2010.

[11] Cengel, Y., Heat Transfer: A Practical Approach. 3 ed., USA: McGraw-Hill, 2003. 


\section{تأثير استخام السقف المعلق على الحمل الحرارى للسقف}

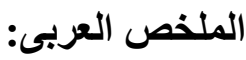

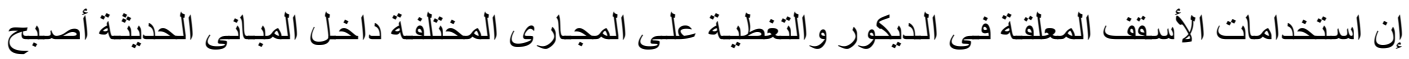

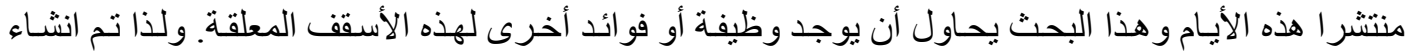

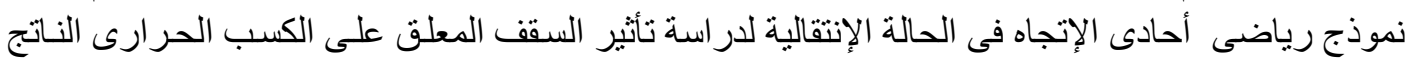

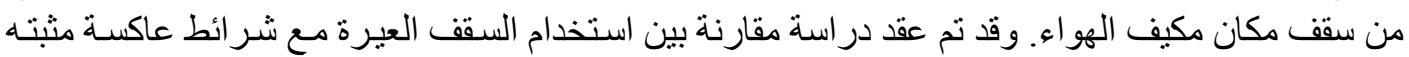

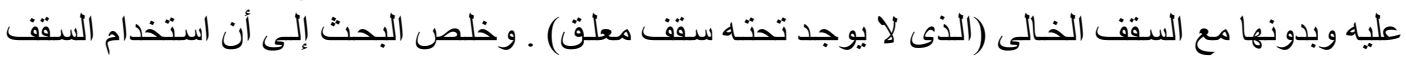

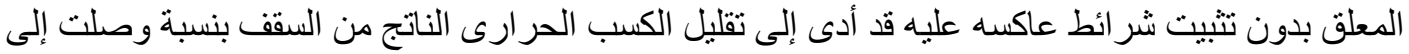

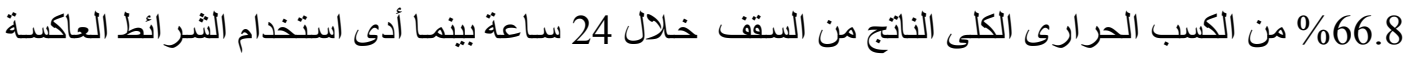

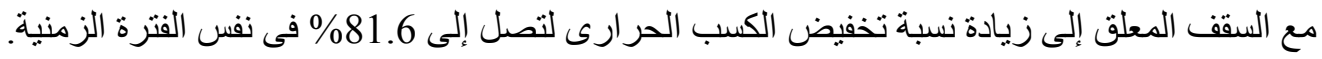

